Die Teilnehmer selbst wissen also nicht, ob sie die Mutation haben?

Danek: Sie haben das Recht, das zu wissen, aber nicht innerhalb der DIAN-Konstellation. In den USA erhalten sie eine Adresse, wo sie es erfahren können und eine humangenetische Beratung erhalten. Wie wir damit in Deutschland umgehen, müssen wir noch klären.

Wie weit ist das Projekt?

Danek: Insgesamt wollen wir 400 Teilnehmer aufnehmen. In den USA, Großbritannien und Australien konnten bereits etwa 200 Teilnehmer gewonnen werden. In Deutschland fangen wir erst an, und zwar in Tübingen und München, weil nur da derzeit eine AmyloidPET möglich ist. Zudem ist es uns gelungen, beim Deutschen Zentrum für Neurodegenerative Erkrankungen in Bonn finanzielle Unterstützung zu beantragen. Derzeit arbeiten wir an Übersetzungen der neuropsychologischen Protokolle und holen Voten der Ethikkommissionen ein. In Tübingen gibt es schon ein positives Ethikvotum. Das Besondere dabei ist ja, dass auch Probanden ein PET bekommen, von denen die Ärzte nicht wissen, ob sie Genträger sind. Die Frage ist nun, wie viel Strahlenbelastung darf ich einem Gesunden hier zumuten? Bei den Therapien ist es zumindest so geregelt, dass alle Teilnehmer ohne Genmutation in die Placebogruppe kommen, aber auch ein Teil derer mit Mutation.

Wie kommen Sie überhaupt an geeignete Studienteilnehmer?

Danek: Das ist nicht einfach. Verdacht auf eine familiäre Erkrankung besteht, wenn jemand unter 60 Jahren ist und schon früher jemand in der Familie erkrankt ist. Dann aber nach Mutationen in der Familie zu suchen, wird von den wenigsten Ärzten gemacht, und das liegt nicht nur an den Kosten. Denn die Kollegen fragen sich: Wem nützt es, wenn wir einem Angehörigen sagen können, er wird in zehn Jahren auch erkranken? Wir können die Humangenetiker nur bitten, dass sie die Getesteten im Beratungsgespräch auf DIAN hinweisen und Infomaterial dazu auslegen. Oder man muss DIAN so bekannt machen, dass jemand, der getestet worden ist, von sich aus zu uns kommt.

Kann eine familiäre Erkrankung auch erst im höheren Alter auftreten?

Danek: Ich hatte einen älteren Herrn, über 70 Jahre, der eine Demenz mit einer spastischen Paraparese entwickelte - wie zuvor sein Bruder. Diese Kombination gibt es bekanntlich bei Presenilin-1-Mutationen. Da habe ich gesagt, das ist so verdächtig, das will ich jetzt testen.

Es könnte also sein, dass eine familiäre Alzheimer- Demenz wesentlich häufiger auftritt als angenommen, weil man bei älteren Patienten normalerweise nicht daran denkt?

Danek: Wesentlich häufiger würde ich nicht sagen, es sind wohl schon eher die Jüngeren, aber es gibt beim Manifestationsalter eben eine gewisse Variabilität. Wie viele tatsächlich eine Mutation tragen - dazu gibt es keine vernünftigen Schätzungen, weil die genetische Diagnostik viel zu selten genutzt wird.

Das Gespräch führte Thomas Müller.

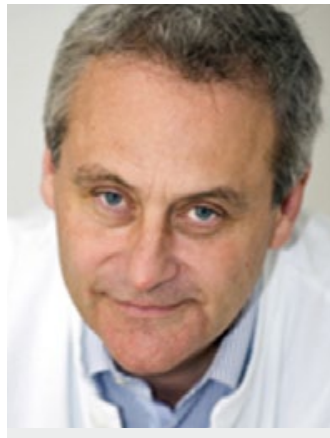

Professor Dr. med. Adrian Danek ist Leiter der Arbeitsgruppe Kognitive Neurologie an der Neurologischen Klinik der Ludwig-MaximiliansUniversität in München. Dort leitet er auch die Gedächtnissprechstunde (Sprechstunde Kognitive Neurologie) am Klinikum Großhadern.

\title{
DIAN und familiäre Alzheimer-Demenz
}

Die Erkrankung: Einige seltene Genmutationen können kausal eine AlzheimerDemenz auslösen. Alle diese Mutationen befinden sich in nur drei DNA-Abschnitten: im Gen für das Amyloid-Precursor-Protein (APP), für Presenilin 1 und Presenilin 2. Diese drei Gene sind am Amyloidstoffwechsel beteiligt. Bei allen Mutationsträgern kommt es sehr früh zu einer Anhäufung der Alzheimer-typischen Amyloidplaques, und alle erkranken ab einem bestimmten Alter an einer Demenz, meist vor dem 60. Lebensjahr.

Das Projekt: DIAN steht für „Dominantly Inherited Alzheimer Network". Die Initiative wurde in den USA vom Alzheimer-Forscher John C. Morris aus St. Louis gegründet, um die genetisch bedingten Krankheitsformen besser zu erforschen. Die Teilnahme steht
Personen aus Familien offen, in denen solche Formen nachgewiesen wurden. Derzeit werden an elf Standorten in den USA, einem in London und drei in Australien Studienteilnehmer aufgenommen. Geplant sind auch Standorte in Deutschland - zunächst München und Tübingen (Professor Mathias Jucker und Professor Christoph Laske) - sowie in Spanien.

Die Untersuchungen: Erforderlich sind Kognitionstests, Blut- und Liquorentnahmen inklusive Gentests, bildgebende Untersuchungen per MRT sowie PETAufnahmen, unter anderem mit dem Biomarker Pittsburgh Compound B (PiB), der Amyloid-Ablagerungen im Gehirn sichtbar macht. Die Testintervalle hängen vom Alter der Teilnehmer ab. Je näher sie an das Alter herankommen, in denen die
Demenz in ihrer Familie auftritt, umso kürzer werden die Abstände - bis hin zu jährlichen Tests.

Die Ziele: Ein besseres Verständnis der Alzheimer-Demenz. Erkenntnisse aus DIAN sollen die Entwicklung von Frühtests für alle Alzheimer-Formen beschleunigen. Zudem werden den Teilnehmern Präventionsstudien mit neuen Medikamenten angeboten. Damit lässt sich prüfen, ob der Ausbruch der Erkrankung durch Medikamente verhindert oder verzögert werden kann.

\section{Weitere Informationen} geben die Koordinationsbüros München (Telefon 089 7095-4828) und Tübingen (Telefon 07071 29-81928) sowie www.dian-info.org/de, www.dian-info.org 